\title{
From Figurative Painting to Painting of Substance - The Concept of an Artist
}

\author{
Zdravka Vasileva \\ National Academy of Art - Sofia, Faculty of Fine Arts, BULGARIA
}

Received 26 April 2019 • Revised 24 August 2019 • Accepted 5 September 2019

\begin{abstract}
This article aims at a brief analysis of the artistic processes in Bulgaria during the discussed decades, and it is also an attempt to pinpoint the stages in the work of the artist Petar Dochev (1935-2005) in the respective period. The stages and the changes in his work are not considered as an end in itself, but on the one hand as a part of the dynamics in the Bulgarian fine arts, and on the other - as an artistic practice which is fundamental to the work of some contemporary Bulgarian artists and, which further develops the experience of the abstract and informal art in Bulgaria. The main problem in the text is also provoked by the fact that the trends in the contemporary Bulgarian painting (from the mid-9os to present day) draw our attention more and more to objects of the so-called "conceptual" painting and other forms of visual arts (video art, digital arts, conceptual art, etc.), while there are still no deeper studies of the informal and the abstract.
\end{abstract}

Keywords: abstract, informal, Bulgarian art, painting, experiment.

\section{Introduction}

The dynamically changing visual environment and the active use of various forms of communication with the audience, sometimes causes ambiguity and doubt about the quality of a certain work of art and its message. The timeline discussed in this text - from the 1960 s to the beginning of the 21 century, is far from the problems and the current state of art, but it is the reason for them. There are many books dedicated to the contemporary Bulgarian art - its development and transformations, the desire and the realization of "catching up" to the Western European art. However, the important here is not the outlining of a practice that has evolved regardless of the limited parameters - conceptual, ideological, socio-cultural or technological. Petar Dochev is an artist whose strong but unobtrusive presence creates a lasting tendency in the contemporary Bulgarian painting. As a student he leaves the academy disagreeing with and refusing to adapt to the strict academicism. His personal and professional predicaments take him to the Kremikovtzi factory, where he starts working as a slogan and poster artist. In this industrial giant, Dochev develops his technology and paintings with a new iconographic system. In the mid70s, he leaves this place and devotes himself to his personal work and experiment. He spends the last twenty years of his life (1985-2005), in his birthplace in the village of Lesidren, where he paints some of the innovative and contemporary works in the Bulgarian art.

Over the decades, the painting in Bulgaria has a different status: from a place of honor in the exhibitions with large-scale figurative compositions with labor as subject matter in the

(C) Authors. Terms and conditions of Creative Commons Attribution 4.0 International (CC BY 4.0) apply. Correspondence: Zdravka Vasileva, National Academy of Art - Sofia, Faculty of Fine Arts, BULGARIA. E-mail: vasileva@bitex.bg. 
1960s, through elite salons and exhibitions for experts and collectors. The democratic environment largely creates the illusion of change, but in this freedom there emerge artists and "works" with controversial qualities and taste; nowadays the painting exhibitions are ignored and not widely publicized, which is why the very young artists, instead of unflinching enthusiasm, have doubts about their work. The monographic approach is intended to prove clearly that despite the wide open and dynamic cultural environment, the focus on painting as media and art, has not been shifted. The topic is specific and concrete, and in this sense there is well used chronological analysis of the time, and parallel to that of an artistic practice, making the thesis clearer and constructive.

\section{Psychological portrait of the man}

When discussing the figurative/visual art, we need to recall the role of the sociocultural context - the social, political and cultural environment, shaping the trends in the Bulgarian art in particular the painting. The 1960s are controversial and interesting period in the Bulgarian art - because, on the one hand, it strives for something new, related to the rejection of the former academicism and thematics, and on the other, it can hardly ignore the model imposed during the previous decade. Until then we could see large-format multi-figure compositions dealing with production themes - workers in workshops and factories, marching in festive procession, or portraits of political leaders. The purpose of this political "cultural program" is the art to be close to the people (accessible and understandable) and to illustrate the beautiful and smiling working day. So change is difficult for both the artists and the audience. The painting has the ambition to deal not only with a new understanding of plasticity, color and shape, but also to be a work of art that reflects different trends, and an individual author's approach. The narrow understanding of the figure and the subject matter also changes, and the foundations of that trinity of "time, place and action", which until now has been decisive for the works of art, have gradually changed. Obviously, the changes in the early 1960s are a long and gradual process. The resorting to the folklore and the traditions by this particular generation of artists has a positive effect on art, and is a part of the attempt to "justify" the formalism. In this attempt the Bulgarian art starts to get close to some models of the Western art, albeit from much earlier years.

\section{1}

These years coincide with the first artistic stage of Petar Dochev, and this is the time when he participates in group exhibitions with his first works. The first paintings by P. Dochev are also executed with the typical for the 1960s subject matter and stylistics - portraits and figural compositions from Kremikovtzi. The interesting in his works, however, is that he does not imply "the ideas of the new time", instead, he saturates his canvases, seals the states presented in them and overlaps the meaning embedded in them, through compositional and plastic solutions, outside the generally accepted framework. Normally, the figurative compositions depicting labor themes, are filled with the obligatory optimistic spirit, the characters (always positive), are very often reminiscent of the characters of the compositions of the socialist realism. Unlike them, Dochev's approach carries something different, as he deliberately deviates from the usual for this kind of paintings. His attempt to make a general psychological dissection of the character type, and to unite it around a state that goes beyond a particular portrait and without any details, is remarkable. The focus here is on the psychological "study" of the group. The comments on the artist's paintings from this period are united by the view that they undoubtedly have qualities, both in purely artistic terms and as "documentary" of the time. The critical texts on his canvases from this period (though contradictive), mark his innovative approach to the depiction of the labor as subject, and the creation of a new "iconography" in the figure painting. The monumentality, the plastic and psychological generalizations, the innovative style that becomes a distinctive feature 
of his works, are all qualities that always help us to recognize his figurative compositions, and give him a special place in understanding and the rationalization of this subject.

\section{The industrial theme - a zone of experiment}

What can be noted as a specific feature of the next decade, is related to the stylistic diversity (photorealism, naivism, primitivism, etc.), and to a line in the Bulgarian fine art, which finds its rather vague terminological formulation in the so-called associative-metaphorical painting. At that time, art tries to break the system of realism and to bring something new (locally). The new trends, however, are labeled as poor assimilation of the foreign experience, and are often rejected and unaccepted, because of their departure from the artistic conventions regulated in the past practice. Despite the fact that in the course of the discussions a number of world artists are mentioned as probable models of impact on our artists, in practice the Bulgarian art continues to develop in a relative isolation from the world tendencies and the current interest.

\section{1}

At the end of the 1960s and 1970s, although hardly chosen by the authors because of its unfriendliness, severity and coldness, the industrial landscape takes a solid position. This genre is probably preferred because of the relative freedom and distance from the thematic picture. The difference in the case of Petar Dochev is that he is able to distance himself from the expectations associated with such a landscape, and to make a contemporary work, beyond the usual documentary and the political pathos of the idea that "new life is being built". It is this artist who builds up a strong state for the industrial site. Petar Dochev's work from this period is related to the tendency to estheticize and psychologize the industrial painting, an occasion for plastic search and experimentation - for a distant study of the specific object. Many critical analyzes note the artist's interesting approach and his consistency in bringing up a separate line in this genre. Dochev does not paint landscapes from life, but creates paintings without any relation to the time and space, in which he designs numerous scaffoldings or machines, painted in close-up. The conditional use of the from-life, is an approach to an innovative method of work and an interesting technique, which he uses here (and later in his abstract compositions) - blending oil paint with graphite - graphite grey powder, which is waste material from the Kremikovtzi plant. Added in the paint or in pure form, this filler gives volume, density and structure to the works. Starting gradually with the "from life" painting, Petar Dochev starts experimenting with the accumulation of the painting material, with the display of monochromatic color values, with the conditional marking of terrains and the use of light as a meaningful accent. From the initially generalized and monumental presentation of the nature with the particular psychological and philosophical suggestion, the artist comes to paintings, where the main point is not the subject matter and the form, but the play with the plastic components and the construction of a new author concept.

\section{The abstract as a problem}

The processes in the Bulgarian fine art in the 1980s are particularly dynamic and diverse. In addition to the overcoming of the associative-metaphorical anachronistic way of thinking in the fine arts, a special moment in the specificity of the Bulgarian art scene from the period, for example, is the emergence of the so-called unconventional forms. The accent in painting is the concept of "abstract", with which many individual art practices are associated. Often, however, this non-figurativeness is not perceived by the artists as a follow-up to the form and related to the analysis of color, matter, or gesture, but it is rather seen as a random combination of stains, colors and techniques. (This vagueness is also sensed in the titles often 
given to some of the abstract paintings from the period, for example: Cosmos, Mood, Dream, Music ...). In the painting of the 1980s, several parallel artistic and plastic lines are categorically identified, which in the critical texts are often recognized as stylistic "diversity". Tendencies towards expressiveness, abstraction, or hyperrealism are increasingly emerging. Later, this interest is largely justified by the artist's desire for freedom in the use of the means of expression, as he has long been trapped between his own needs and thematic frames.

\section{1}

In his paintings from the 1980 s Petar Dochev, fully in line with his personal creative and research interests, gradually transforms the constructivist forms from the industrial motifs into solid, material and generalized compositions with color accents. With the departure from the gray industrial area, the artist turns his look at the city, the earth, and the nature, but if in the past the distance to the object was shortened so the industrial can dominate over the poetic, now we look through a bird's eye - there is no specificity and detail. The free association makes the viewer link these canvases to his landscapes from previous years, but they could be a completely abstract composition, in which the silhouette of the specific is lost. This idea of the impact of the material and the use of its physical qualities for the transmission of a specific suggestion in the absence of a concrete reality, is a problem that Dochev deals with permanently

For Petar Dochev the interest in the abstract does not come suddenly, as a result of the influence of a common artistic process. In his individual artistic stages, this is a long and deliberately provoked and rationalized act of his overall painting system, and author's method. The abstraction is not only a modern and interesting concept, but an idea that unites the spiritual philosophy of art and life, and that is precisely how Dochev understands it. An example of this are the paintings that he begins to make in the mid-1990s.

\section{Paintings - Icons}

The perception of the painting (after the political changes of 1989 and the specifics of the visual of the period) starts to change and expand its significance in the context of the time, and the contemporary criticism more and more strives to conceive and analyze such concepts and categories as "conceptual painting", "informal", "post-painting”, etc.

It becomes clear that in the Bulgarian art the 1990s are a time of free, parallel coexistence of the varieties of the abstract painting, surrealism, photorealism, and neoexpressionism, as very often their techniques intertwine in the same work, or in the works of the same author, the reason for which is perhaps also the lack of conceptual clarity. The experiments of some artists with different materials, bases, and fillers (ash, dry pigment, sand, graphite, resin, etc.) in order to achieve a greater sensitivity and suggestion, are associated with the informal art. What is observed as a trend in the Bulgarian art, is in fact and in its own way, a "late" version of the informal, in which the "native" is deeply embedded, and moreover, it occurs at a time when the influence of the painting itself is very much disputed by artists and critics. It is important to clarify that all of these artistic practices, styles and categories are of a local nature (they are inherently related to the place, the time and the sociocultural context), different than the Western European art.

\section{1}

Over the last few years, many authors became interested in the large-scale monochrome painting, which also attempts to change the "status" of the visual art and the painting 
in general. These canvases seem to bring back the understanding of it, as something elitist, and distinguish it from the standard notion of the decorative and "fine" art. In the informal the white, the black, only a single color or media are enough to make painting. The accents in this type of works are the reflected light, the texture, the relief of the black, as well as its halftones, its transparency or depth. Building the texture, in the sense of a material form and a space on the canvas (or on other media), depends on the choice of material. Very often the specific plastic and technological characteristics of the material predetermine the idea of the author, in other times the conceptual message precedes and directs the choice of means for its realization.

The abandoning of the specific imagery, the accent on the texture, the structure and the demand for a pure sensuality, gives us grounds to consider the paintings of Petar Dochev as a serious experience in the informal in Bulgaria.

The artistic search of the artist is consistent and follow the natural rationalization of a timely visual direction. By reducing the various plastic techniques in his work, he achieves a synthesis of the form that distinguishes his paintings from everything he has done so far, and provokes our perceptions. His specific way of using the line and the color, dating back from his industrial landscapes, and later with the distancing from the construction and bringing closer the plans in his terrains, are most definitely among the most significant innovations in the Bulgarian contemporary painting.

At the height of the debates "pro and against the painting", Dochev makes his graphite works - totally abstract forms, in which the bearer of the idea is only the material. The plastic synthesis in his work and his constant experiment with the variations of these gray-black "shapes" become his personal style, which is fundamental for one line in the contemporary Bulgarian painting from the end of the 1990's to the beginning of XXI century. The dynamics or the confusion of the artistic processes in Bulgaria at the end of XX century testifies to a number of artists, who originally start with the classical painting, and who at some point in their career realize their ideas through the unconventional language, and vice versa, some artists who have tried the tempting territory of the unconventional forms, at some point return to the resources of the fine arts. At the beginning of XXI century, the categories of contemporary, avant-garde, abstract, innovative, etc., are much more thoroughly analyzed and explained by artists and critics, and of course this leads to concentration and conceptual clarity about the artists' practices.

\section{Conclusion}

As early as the time of his thematic compositions, Petar Dochev fits only in terms of genre, but not emotionally, in the requirement for ideological commitment in the presentation of the subject. Later on, starting from the conditional form of the industrial constructions, he builds paintings that are new, not because the environment that serves him as object has new appearance, but because he creates a different reality, recreated through innovations in the use of the language of painting. At a later stage he abandons the monochrome works, but he is only briefly lured by the color, only to rediscovers the brilliance of the solid graphite surface. And although at the end of the 1990s, P. Dochev is not a young artist, he is open to the new and the unknown, always ready to experiment, search and discover. Usually such need is not typical for artists with already established plastic concept, except for the cases when the concept demands this, and when it is associated with specific rationalization of the means. In the works of Petar Dochev, however, the experiment is in the deep meaning and the philosophy of the work. From the late 1990 s to the last, anniversary exhibition in 2004, he makes large-format compositions (200x200m.), with graphite (and resin) on a wooden panel, others with graphite, foil and paint, and the last ones only with gold pigment. This "state" of the painting - its highly material surface - often calls not only for decoding of its semantic layers, but also to be felt and touched, understood not only visually but also sensitively. The painting, which focuses primarily on the substance, is actually perceived as 
something "immaterial", a world of the transcendental, the spiritual, the existential, and its surface is "read" as a substance-idea. The last golden paintings are not only "icons of the spiritual", but an ending of a conceptual system, to which Dochev aspires over the years, and which is a qualitatively new stage for the contemporary Bulgarian painting. Dochev's language becomes even more laconic and strong, making it universal. Without ambition and claim for plastic discovery, the author perceives his work as an expression of the spiritual side in art, and entirely devoted to that, he reaches the synthesis in which the laconic means of expression have a strong effect and profound meaning.

\section{Biographical notes}

Petar Dochev was born on 6 October 1934 in the village of Lesidren, Bulgaria.

1959 - Leaves the Academy of Art in Sofia.

From 1959 to 1975 he works as chief artist of Kremikovtzi Metallurgical Works.

1970 - First solo exhibition in Kremikovtzi.

Participation in collective exhibitions - 1973 Szczecin, Poland; Paris, France; Moscow, Russia; 1978- Bologna, Italy; Belgrade, Serbia; 1980- Athens, Greece; Berlin, Germany; Havana, Cuba; Bucharest, Romania; 1983 - Algeria, Tunisia and Kuwait; 1990- Brussels, Belgium;

2001 - Layers - Irida Gallery, Sofia, Bulgaria.

2003 - (R)evolution - curatorial project of Irida Gallery, Sofia.

2004 - Achroma - curatorial project, Sofia.

2005 - International Biennial of Contemporary Art Prague, Czech Republic.

2005 - Exhibition Earth, Circle + Gallery, Sofia.

1975 - Leaves Kremikovtsi and works as freelancer. The same year, he attends a workshop at Cité Internationale des Arts, Paris, and has the opportunity to meet the great French painter Pierre Soulages. Later, the Spain's cultural attaché, who owns about 30 paintings by Dochev, helps the artist to meet with the great Spanish artist Antoni Tàpies in Madrid. to live in Sofia.

1978 - Petar Dochev builds his small studio in the village of Lesidren, but continues

After 1966 he actively participates in collective and solo exhibitions, as well as international participations. In the late 1980 s, for seven years, the artist does not show and exhibit his works in exhibitions, the reason for this is the commercialization, mediocrity and the replacement of values, while he perceives his work as an expression of the spiritual and the sublime in man. In the mid-1990s, after the rehabilitation of the large-format painting and the change in the status of the painting, the interest in his art makes him among the significant national and international projects for contemporary art. Between 1985 and 2005 he lives and works in his home village Lesidren. He dies in 2005. 

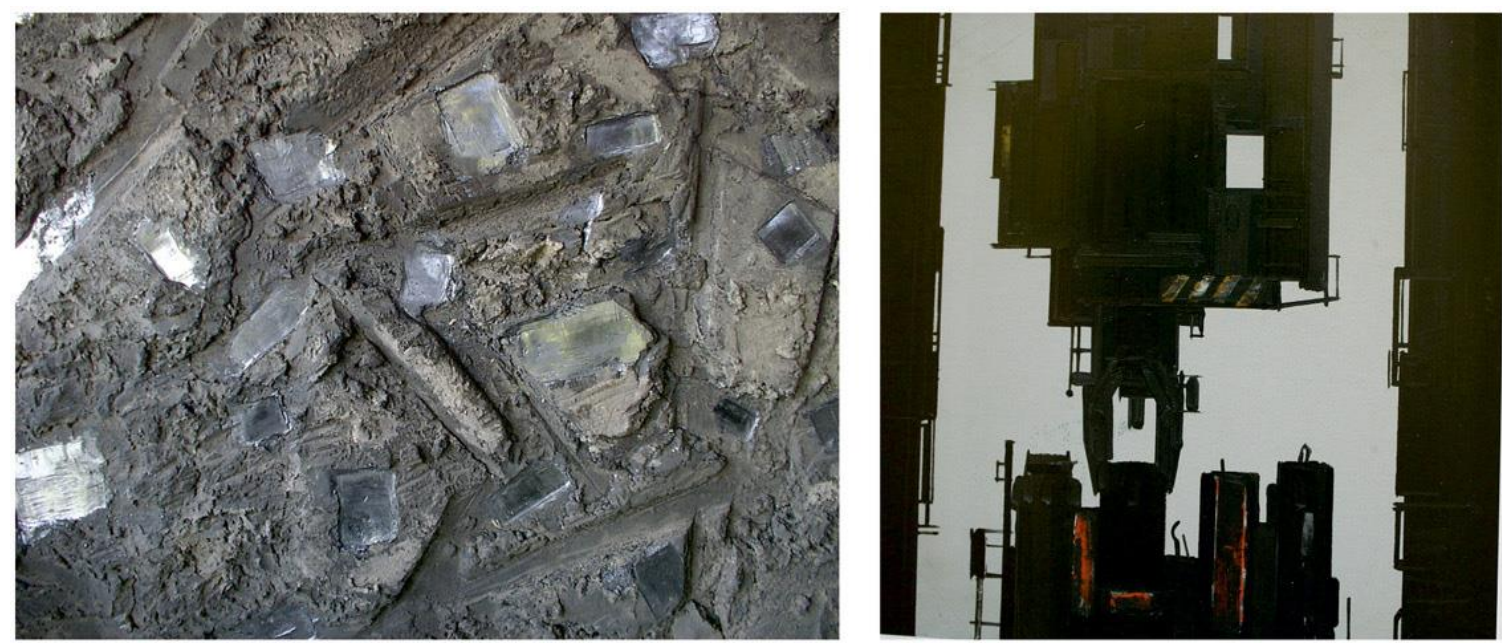

Composition, mixed media, graphite on plywood, 200x200, 2002 - detail Kremikovtsi Metallurgical Complex, oil on canvas, 130x130, 1970's
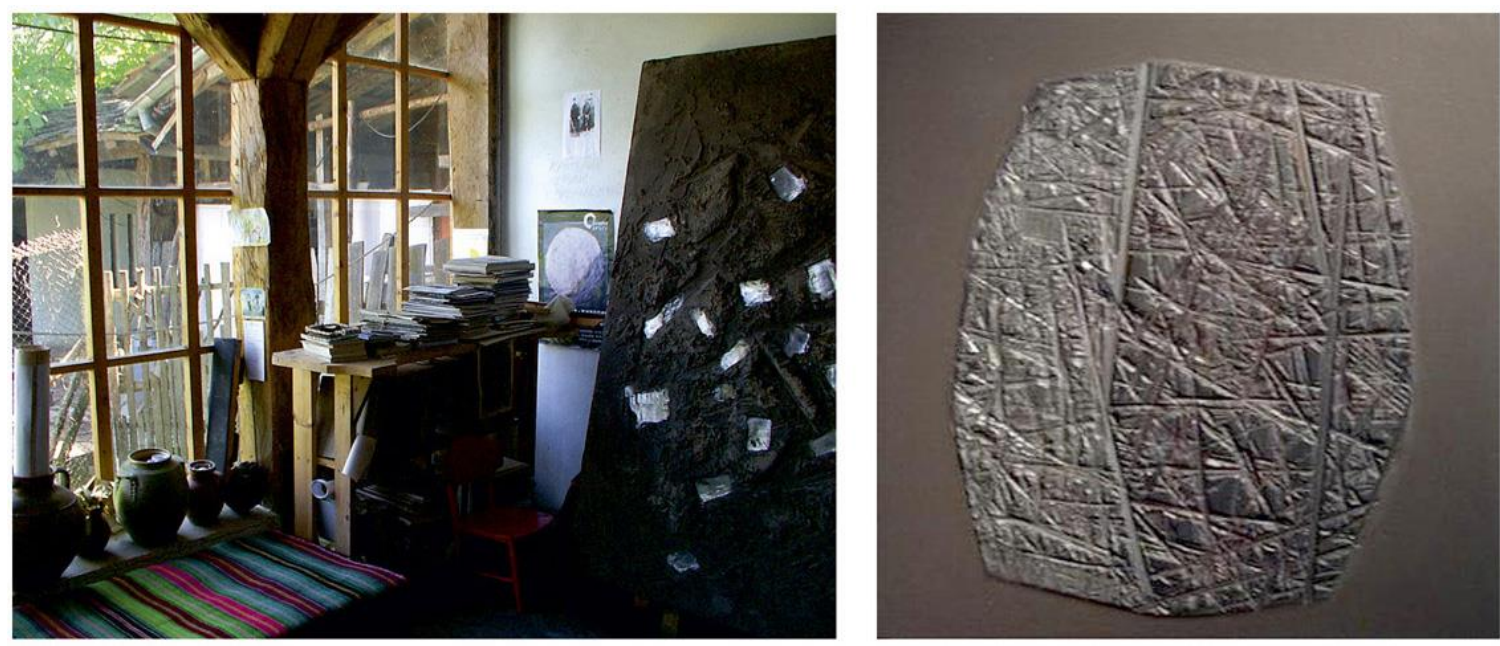

Dochev's Studio in Lesidren Shape, mixed media, silver, plywood, 100x100, 2000

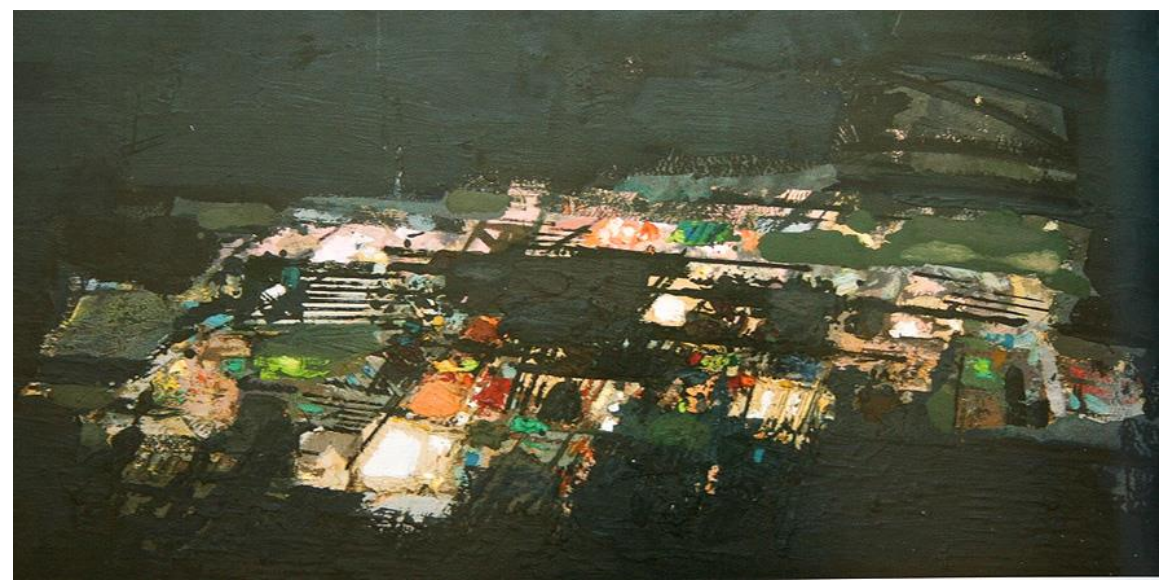

Transformed Land, oil on canvas, 70x140, 1983 


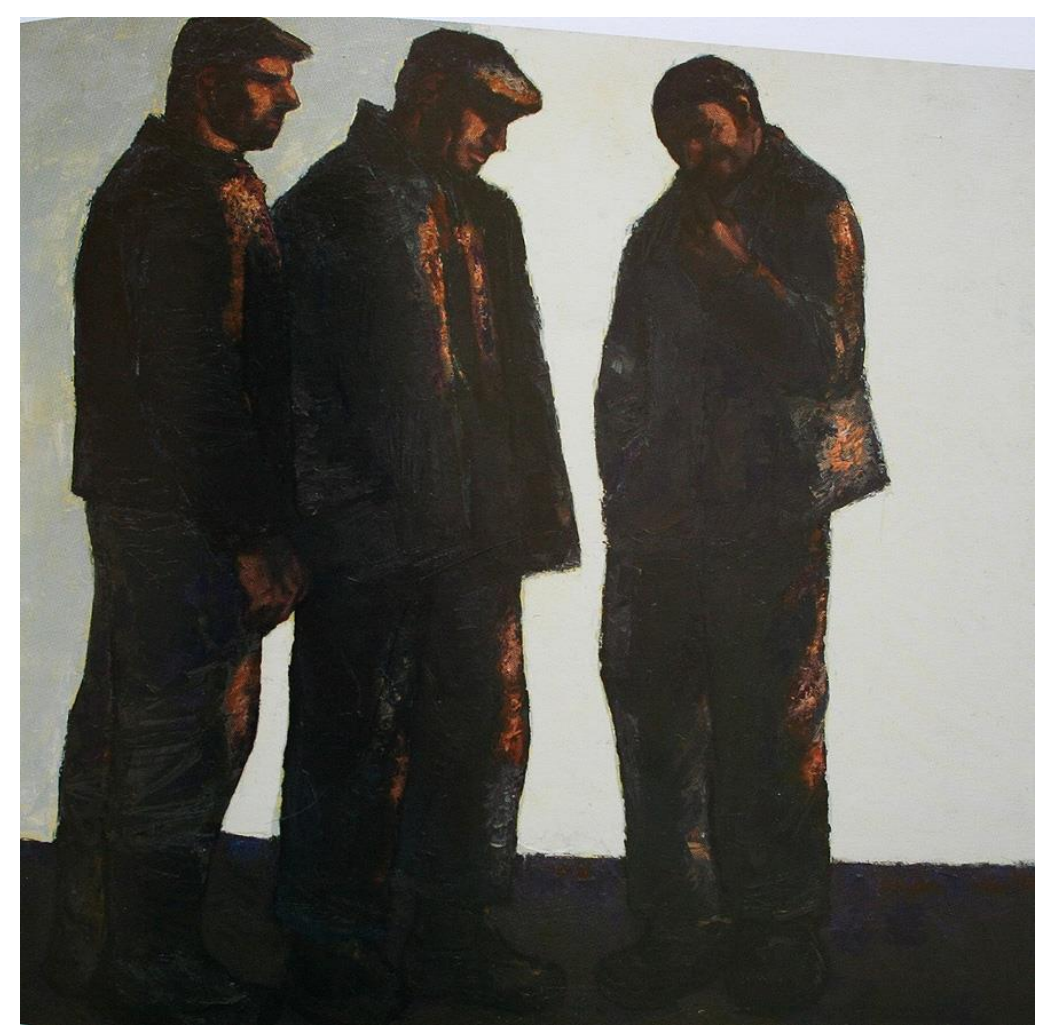

Metallurgical Workers, oil on canvas, 1960’s
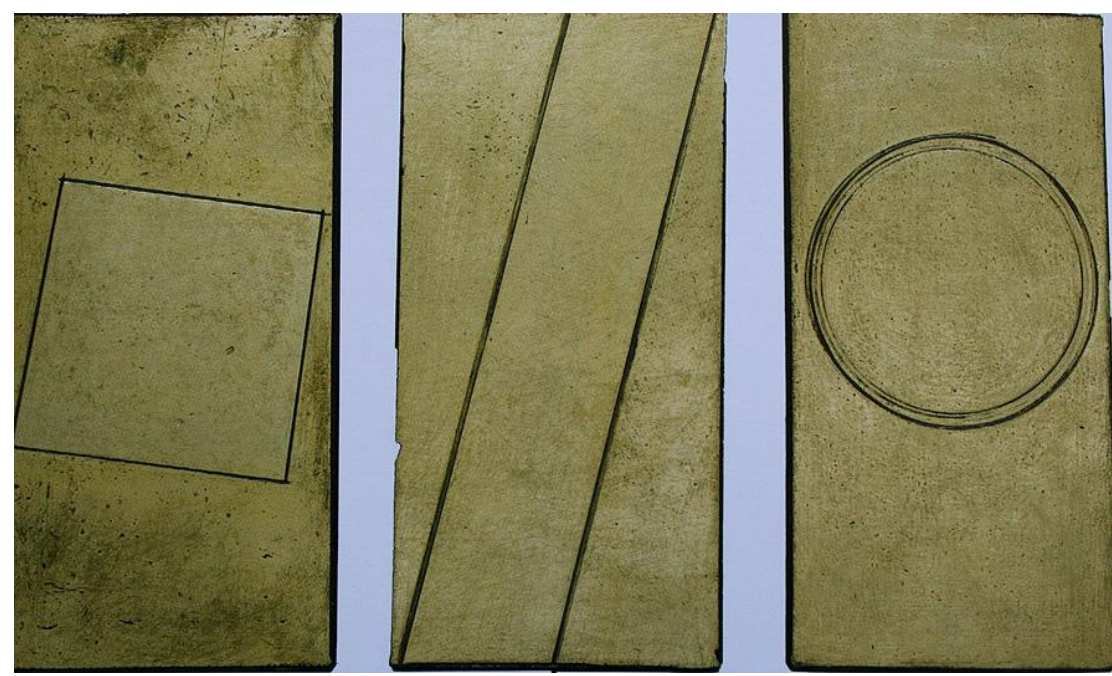

Tryptich, mixed media, gold, plywood, 100x150, 2004

\section{Summary}

The Bulgarian art from the 1960s through the 1990s, is quite dynamic and diverse in terms of trends and individual practices. At the beginning of this period there was a "relaxation" and abandoning of the established normative rules in the construction of the painting. Perhaps then there is a most direct and strong connection between the sociopolitical and cultural environment, and the fundamental change is there only seemingly. The decades to come also bring 
confusion, the reason for which is, on the one hand the suggestion of freedom and new directions and, on the other, the legacy of the past in terms of ideology and mindset. The article From the figurative to the painting of the substance - the concept of an artist, outlines chronologically, in parallel to the sociocultural changes in the artistic life, the interesting, innovative practice of a contemporary Bulgarian artist - Petar Dochev (1934-2005). Regardless of the traditions, the normative rules and the academicism, the artist even then searches and demonstrates a way to circumvent them, and to direct his work towards modernity and unconventional methods in painting - plastic and technological. The article follows the stages in the trends of the Bulgarian fine art of the respective decade, as well as the gradual and rationalized change in the concept of the painting of the artist P. Dochev.

\section{Acknowledgements}

This research did not receive any specific grant from funding agencies in the public commercial, or not-for-profit sectors.

The author declares no competing interests.

\section{References}

Avramov, D. (1967). Problems of the plastic language of painting. On some perspectives in aesthetics of abstractionism. Art Magazine, (9 \& 7).

Avramov, D. (1968). Destruction of the image. Three phases of the development of the aesthetics of abstract painting. Art Magazine, (1 \& 3).

Avramov, D. (1969). Aesthetics of modern art. Sofia.

Avramov, D. (1975). On some style trends in the contemporary Bulgarian painting. Art Magazine, (2).

Avramov, D. (1994). Chronicle of a dramatic decade. Sofia.

... (2003). Bulgarian Art in the 1990 os between the traditions and innovations, Collection of articles, edited by Chavdar Popov, Svilen Stefanov. Sofia.

Dimitrov, G. (1983). Dimitar, The landscape in contemporary Bulgarian painting - Problems and perspectives. Art Magazine, (5).

Dzhurova, A. (1970). On some problems of the figural composition. Art Magazine, (2 \& 3).

Lecture by Pierre Restany (1996). Sofia, 16.11.1996, in connection with the triennial - Sofia '96. Art Magazine/ Art in Bulgaria, (38-40) 1996.

Marazov, I. (1982). Problems of painting. Art Magazine, (3).

Marinska, R. (1984). On the boundaries of the plastic. Art Magazine, (4 \& 9).

Popov, C. (1993). Some Aspects of the Evolution of the Overcoming of the social realism: hero, character, antihero. Art Problems Magazine, (2).

Restany, P. (1993). Art in the public space: modern nature and post-industrial sensitivity [translation Ekaterina Takova]. Art Magazine/ Art in Bulgaria, (6).

Stefanov, S. (2001). The art between tradition and provocation. Sofia.

Stefanov, S. (2003). Avangard and norm. Sofia.

Stefanov, I. (2004). From aesthetics to sociology of art. Sofia. 
Z. Vasileva - From Figurative Painting to Painting of Substance - The Concept of an Artist

Stefanov, S. (2014). Innovations in the Bulgarian art from the end of the XX century and the beginning of the XXI century. Sofia. (articles from magazines) 